\title{
CORRESPONDENCE.
}

\section{THE MEASURE OF EXPENSES IN LIFE ASSURANCE COMPANIES.}

To the Editor of the Journal of the Institute of Actuaries.

Srn,-Mr. Macfadyen, in his paper on the above subject, read before the Institute in May last, made special reference to a paper contributed by me to the $\bar{J}_{0 u r n a l}$ for October 1874, and did me the honour of coupling my name with that of Mr. Sprague, as an originator of a new way of looking at the expenses of life offices. Mr. Macfadyen takes the view that Mr. Sprague and I contend " that " a certain amount of the total outlay should first be set against the " new premiums, and that the order of the companies in economy of " management should be settled by the ratio of the remaining expen" diture to the renewal premium revenue." Mr. Sprague has already stated, in a letter to the Insurance Record, that the above quotation does not correctly represent his views; and for myself, I have to say, that I could on]y adopt this method of ranking the companies if I believed the initial expenditure in all companies to be uniformly the same; but I am satisfied this is very far from being the case. What I really contend for is, that the initial and renewal expenses should be stated separately, and that they should be set against the new and renewal premiums respectively. A tabular statement made up in this way, containing in two columns the percentages of new and renewal premiums expended in acquiring and managing the business, would at least be greatly preferable to one made up in the ordinary way. Whether the final result of the two columns could be satisfactorily given in one column, as indicated by Mr. Macfadyen, would depend upon circumstances. My own feeling is that, instead of starting with the assumption of a fixed charge on the first premiums, it might be found more convenient to assume a fixed charge for renewal expenses, (as there is probably less variation in the renewal expenditure of offices than in the initial expenditure,) and rate the offices according to the amount 
of initial expenditure for each $£ 100$ assured. Owing to special circumstances, a considerable number of offices would require to be excluded from a general comparison made in this way; but it seems to me that it might be fairly applicable to a large section of the offices transacting business on similar principles. At all events, it is in this latter form that the method seems capable of being applied, at the head office of a company, in testing the expenses at its various district agencies. It first suggested itself to me some years ago, when I happened to be looking into the expenditure at various branch offices, some of which nad been many years in operation, while others had been established only a year or two. Reckoned in the ordinary way, the expenses at the different branches exhibited widely varying percentages, and it was easy to see at a glance that they afforded no indication of the relative success of the branches. The object of these branches, or district agencies, being the acquisition of new business, rather than the management of the business after it had been acquired, and the renewal commission paid to the ordinary sub-agents in the district being the same in each ease, it seemed clear that the proper course to adopt was first to eliminate from the accounts the renewal commissions and the renewal premiums, and then to charge the whole of the remaining expenditure in each district against the new premiums obtained in that district. Subsequently, it was found better to exhibit the expenses on each $£ 100$ of new sums assured, in order to avoid reckoning separately policies effected by limited payments, \&c.

So simple and self-evident do these views appear, that I scarcely think they require to be supported by argument. I should think they must have occurred to many actuaries in the course of their investigations, and I do not anticipate the evil results from their publication which Mr. Macfadyen dreads. The actuaries who take the opposite view, admit that the expenses are higher during the first year of insurance, but they deprecate all recognition of this fact, either in considering the relative economy of management of the companies, or in fixing the principles to be adopted in the valuation. It seems to me that this is taking rather a narrow view of the subject, and one which can scarcely be defended, either on theoretical or practical grounds. To give an illustration, let us select one item in the initial expenses-namely, the fee paid for the medical examination of the life proposed for insurance. This is undoubtedly a non-recurring expense; but if the arguments of the gentlemen to whom I have alluded, be carried to their legitimate conclusion, no separation of this should be made from recurring expenses, and at the valuation a reserve should be made for the fee, as if it had to be paid over again in each year during the continuance of the policy!

$$
\text { I am, Sir, }
$$

Your most obedient servant,

Edinburgh, 29 Dec. 1875.

D. DEUCHAR. 